\title{
Oral Corrective Feedback in an Intermediate EFL Conversation Class
}

\author{
Siauw, Melina Febrianti \\ English Department, Faculty of Letters, Petra Christian University \\ Siwalankerto 121-131, Surabaya, East Java, INDONESIA \\ E-mail: mellFsiauw@gmail.com
}

\begin{abstract}
This study was done to find out: (1) the types of oral corrective feedback (CF) strategies used by the teacher of an intermediate EFL conversation class and (2) the pedagogical focus of the oral CF in the intermediate EFL conversation class. This study was limited to oral CF given for grammatical and lexical errors found in the conversation class. The theory used as a guideline in this study was the eight major types of oral CF strategies by Sheen and Ellis (2011), supported by Sheen (2011). This study used descriptive qualitative approach. Video recording and semi-structured interview were used in this study. The writer found seven out of eight major types of oral CF strategies in the conversation class in which Didactic Recast was the strategy used the most. The teacher used the oral CF to correct both grammatical and lexical errors in the class; the emphasis, however, was on grammar. Thus, the pedagogical focus of the lesson is grammatical accuracy despite the fact that it is a conversation class because the teacher provided more oral CF strategies aiming at the learners' grammatical accuracy compared to lexical errors.
\end{abstract}

Keywords: error, oral corrective feedback, pedagogical focus.

\section{INTRODUCTION}

English as an international language has been taught to most learners across the world. In both English as Second Language (ESL) and English as Foreign Language (EFL) countries, English can be found as one of the lessons at schools. In learning a new language, for instance English, learners would need to use and practice the target language. During the learning process, nevertheless, learners would experience making errors. Littlewood (1984) states: "Errors play an important role in learning process. Errors show that the language learners are still building the new knowledge in order to be able to use the language" (p. 17). Therefore, as a response to the learners' errors, teachers provide corrective feedback (CF).

According to Sheen and Ellis (2011), "corrective feedback (CF) refers to the feedback that learners receive on the linguistic errors they make in their oral or written production in a second language (L2)" (p. 593). Lyster et al. (2013) suggest "CF plays a pivotal role in the kind of scaffolding that teachers need to provide to individual learners to promote continuing L2 growth" (p. 1). CF has been a topic that is widely discussed by the researchers of Second Language
Acquisition (SLA); however, it is less discussed in EFL context (Méndez and Cruz, 2012). Thus, this has inspired the writer to do a study of $\mathrm{CF}$, especially oral $\mathrm{CF}$ in EFL context.

The term oral CF itself is further defined by Sheen and Ellis (2011) in a more detail way by explaining that oral CF can be given at the time when a learner produces an oral error in his or her utterance (i.e. online) or after the communication or interaction in which a learner participates is over (i.e. off-line). Therefore, the word 'oral' is defined as learners' oral production. Thus, the term oral $\mathrm{CF}$ in this study is defined as the feedback given for errors found in learners' oral production (Sheen and Ellis, 2011).

The role of $\mathrm{CF}$, including oral $\mathrm{CF}$, has been a discussion among researchers. Researchers have argued that sufficient CF will likely support L2 development (Mackey et al., 2016). The use of CF provides chances for learners to notice the gap between their errors and the correct form (2016). By noticing the gap, learners can integrate the correction into their L2 knowledge (2016). In addition, oral CF can also assist L2 development when learners are given chances to produce outputs or to do selfcorrection (2016). Mackey et al. (2016) explain 
further by stating "self-correction in response to feedback can trigger deeper and more elaborate processing of L2 forms, helping learners establish memory traces that last longer" (p. 502). Thus, the role of oral CF in SLA is seen to be important as it promotes acquisition (Sheen and Ellis, 2011).

In relation to teachers' oral CF provision, Chaudron (1988) mentions: "classroom teachers will likely correct learners' errors either when they pertain to the pedagogical focus of the lesson or when they significantly inhibit communication" (p. 136). One teacher's oral CF might differ from others, and one of the reasons is because different classes would have different pedagogical focus. This means that a teacher might provide oral CF strategies differently when he or she teaches classes with different pedagogical focus. Chaudron (1988) claims that in terms of when to correct learners' errors, pedagogical focus is a "major determinant" (p. 137).

This sparks the writer's interest to look more deeply into oral CF in an EFL conversation class. The writer would focus on finding (1) the types of oral CF strategies used and (2) the pedagogical focus in relation to the teacher's oral $\mathrm{CF}$ in the conversation class. The writer would look further into the classroom activities, including in what kind of activity and to what kind of error (grammatical or lexical) the oral $\mathrm{CF}$ is given to see the link between the oral CF provision and the pedagogical focus of the lesson.

\section{TYPES OF ORAL CF STRATEGIES}

There are eight major types of oral CF strategies by Sheen and Ellis (2011), namely recasts (didactic or conversational), explicit correction, explicit correction with metalinguistic explanation, clarification requests, repetition, elicitation, metalinguistic clue, and paralinguistic signal. Sheen and Ellis (2011) classify all major types into two categories: input-providing and output-prompting. These categories are made based on the oral CF strategies, whether they are provided along with the correction (i.e. inputproviding) or they act as feedbacks to prompt correction from the learners (i.e. output-prompting). The explanation for each type and examples supported by Sheen (2011) are provided below:

\section{Input-providing CF}

1. Recasts: a type of oral $\mathrm{CF}$ which is defined as "a reformulation of the learner's erroneous utterance that corrects all or part of the learner's utterance and is embedded in the continuing discourse" (Sheen, 2011 p. 2). Recasts might be given only to a part of speech of the learner's error (partial) or to the whole speech of the learner (full) (Sheen, 2011). Recasts can also be 'didactic' or 'conversational' (as mentioned in Sheen, 2011, p. 2; Sheen and Ellis, 2011, p. 593). The explanation for didactic and conversational recasts are provided below:

a) Didactic recast: a type of recast in which "the correction takes the form of a reformulation of a student utterance even though no communication problem has arisen" (Sheen and Ellis, 2011, p. 594). Full or partial didactic recast aims at directing the learner to notice the position of the error (Sheen, 2011).

b) Conversational recast: a type of recast where a teacher tries to restate the utterance according to what the teacher thinks is intended by the learner (Sheen, 2011). It occurs due to the failure in understanding the speaker's utterance (Sheen and Ellis, 2011). It is also common to find this type of recast ends with a question tag, which makes it seem like a teacher is checking on the learner's intended utterance (Sheen and Ellis, 2011).

2. Explicit correction: a type of oral $\mathrm{CF}$ in which a learner is given clear signs that he or she has made an error, and the teacher provides the correction directly to the learner (Sheen and Ellis, 2011; Sheen, 2011). This type of oral CF strategy is usually given by a teacher by saying "No", "It's not X but Y", "You should say X", "We say X not Y" (Sheen, 2011, p. 3).

3. Explicit correction with metalinguistic explanation: the $\mathrm{CF}$ given with not only direct signals and the correction of the error as in explicit correction, but also metalinguistic explanation from the teacher about the error (Sheen and Ellis, 2011; Sheen, 2011). The example of this type of CF can be seen below:

$\mathrm{S}$ : Fox was clever.

T: The fox was clever. You should use the definite article 'the' because fox has been mentioned.

(Sheen, 2011, p. 3)

\section{Output-prompting CF}

1. Clarification request: the type of oral $\mathrm{CF}$ in which "attention is drawn to a problem utterance by the speaker indicating he/she (the teacher) has not understood it (the learner's utterance)" (Sheen and Ellis, 2011, p. 594). Teachers usually say "Sorry?", "Pardon me?", or "I don't understand what you just said" as clarification requests to learners (Sheen, 2011, p. 3). 
2. Repetition: the type of oral CF in which a teacher repeats the learner's speech without giving any clue or sign, such as a high intonation to the error (Sheen and Ellis, 2011). A stress on the repetition is often used to attract the learner's attention as repetition is meant to elicit the correct form from the learner (Sheen, 2011). The example of repetition is provided below:

S: Mrs. Jones travel a lot last year.

T: Mrs. Jones travel a lot last year?

(Sheen, 2011, p. 4)

3. Elicitation: the type of oral CF where "an attempt is made to verbally elicit the correct form from the learner by, for example, a prompting question" (Sheen and Ellis, 2011, p. 594). Elicitation also comes in the form of a teacher's partial repetition of a learner's utterance to encourage self-correction (Sheen, 2011). An example of elicitation is provided as follows:

S: Once upon a time, there lives a poor girl named Cinderella.

$\mathrm{T}$ : Once upon a time, there......

(Sheen, 2011, p. 4)

4. Metalinguistic clue: the oral CF that contains a metalinguistic explanation for the learner's error with no correction to the error as an attempt to prompt the correction from the learner (Sheen and Ellis, 2011; Sheen 2011). The example of metalinguistic clue can be seen below:

S: He kiss her.

T: You need past tense.

(Sheen, 2011, p. 4)

5. Paralinguistic signal: an oral CF strategy where the teacher does not use verbal signs to show that the learner has made an error and tries to elicit the correction from the learner (Sheen and Ellis, 2011). A teacher gives signals through "gesture or facial expression" (Ellis, 2009, p. 9).

The types of oral $\mathrm{CF}$ strategies mentioned above would be used as a guideline in relation to oral $\mathrm{CF}$ in this study.

\section{METHODS}

This study used descriptive qualitative approach. The source of the data was the classroom activities and the semi-structured interview with the teacher. The data of the study were derived from the teacher's oral CF, which included the teacher's utterances and gestures, and the result of the semi-structured interview with the teacher.

For this study, the writer chose an intermediate conversation class from an English course in Surabaya. This course was chosen because it has been running for a long time, and it also focuses particularly on learners' grammar and conversation. An observation was done previously in every conversation class in the English course, and there were three teachers of conversation class that the writer observed. The teacher who taught the intermediate level conversation class was finally chosen because the teacher was the only one who made use of CF in the conversation class. Based on the writer's observation, the teacher also seemed to know better about the learners in the conversation class and tended to be supportive in teaching and providing corrections to the learners in the conversation class. It is also further supported by the teacher's experience in teaching English. The teacher has been teaching English for 15 years, while the others were said to be new English teachers. Hence, the teacher was chosen for this study. After getting the permission from the English course, the writer started to collect the data.

The writer collected the data by recording the classroom activities and having a semi-structured interview with the teacher. In total, the writer collected four hours of classroom. Each meeting lasted for 60 minutes. The first classroom recording was recorded using an audio recorder. It was taken during the writer's observation of the conversation class. However, the writer made a change in collecting the classroom activities by doing video recording. The writer thought it would be better to analyze the classroom through a video to make it easier for the writer to see the teacher's oral CF provision, including the teacher's facial expression and gestures. The writer video recorded the classroom activities for three meetings. Other than recording the classroom activities, the writer also did a semistructured interview with the teacher for further clarification of the findings. This interview was carried out to ask the teacher about her oral $\mathrm{CF}$ provision. At the end, the writer collected a total of four-hour classroom recording and a fifteen-minute interview.

In order to transcribe the data, the writer used detailed transcription for the classroom recordings, which included the details of the data, such as pauses, intonation, overlapping utterances, facial expressions and others (Elliott, 2005). For the teacher's interview, the writer used clear transcription where it focused only on the content of the data and would not include details of the data (e.g. pauses, non-lexical items) (2005).

After transcribing the classroom recordings, the writer analyzed the types of oral CF strategies that occurred 
in the class. First, the writer took extracts of the teacher's and the learners' interaction that contained the teacher's oral CF from the transcription. Then, the writer wrote down the type of oral CF that the teacher used and gave further explanation on the teacher's oral $\mathrm{CF}$ along with the classroom activities where the oral CF strategy was given for the learners' errors (grammatical or lexical errors). By doing so, the writer could see how the teacher facilitated oral CF to the learners and see the relation of the oral CF with the pedagogical focus. The next step was to analyze the result of the interview with the teacher that had been transcribed. The interview was analyzed to see the relationship between the use of oral CF and the intention and purpose of the teacher in using the oral $\mathrm{CF}$ strategies. Thus, the writer was the one who interpreted the contents of the data and drew conclusions from it (Dörnyei, 2007).

\section{FINDINGS AND DISCUSSION}

Based on the data of the classroom recordings, the writer found the use of recasts (didactic and conversational), explicit correction, explicit correction with metalinguistic explanation, clarification requests, repetition, elicitation, and metalinguistic clue in the conversation class. Paralinguistic signal was the only strategy that was not found in the classroom. This might be because the teacher had a preference in using verbal $\mathrm{CF}$ that would be clearer for the learners. Another thing is that this study found recasts, especially didactic recasts as the most often used type of oral CF strategies. Further explanation for each type of oral CF strategies is shown below:

\section{Input-providing CF}

\section{Recasts}

A recast is commonly known as "a reformulation of the learner's erroneous utterance that corrects all or part of the learner's utterance and is embedded in the continuing discourse" (Sheen, 2011, p. 2). This type of oral CF strategy is found to be the dominant correction strategy in the conversation class. The result of the teacher's interview also clarifies the teacher's use of recasts. According to the teacher, by directly reformulating the learners' errors, particularly grammatical errors, along with the corrections in a conversation class, she could save more time, and the learners could understand the correction immediately as well. Moreover, the teacher did not need to directly point out the errors that the learners made, which was a safer way to correct the learners without discouraging them. The writer found that the teacher also made use of both didactic and conversational recasts in the classroom. Further details and examples of both recasts are provided below:

\section{a) Didactic Recasts}

A didactic recast is explained as the recast that is given to a learner's error, even if there is no difficulty in understanding the learner's utterance (Sheen and Ellis, 2011). Didactic recast is believed to be more explicit because the teacher's main aim is to correct learners' errors even when there is no communication problem arises (2011). The writer found that didactic recast was the strategy used the most in the class, particularly for treating the learners' grammatical errors. Based on the result of the interview, the teacher showed her desire where she wanted the learners to be proficient English speakers with good grammatical accuracy. She also showed her belief that most of the time when the learners made grammatical errors, it was because the learners forgot about the grammar. As a result, didactic recast was given to remind the learners about the correct grammar although the teacher had actually understood what the learners were saying. Didactic recast was given mostly during exercises or games, and interactions that were related to the material or the topic. Didactic recasts were rarely given during interaction that was not related to the material or the topic. The teacher also provided didactic recasts in both partial and full form. Sheen (2011) defines partial and full recasts as the teacher's provision of recasts by reformulating only the erroneous part of the learner's utterance or the learner's whole utterance. Both partial and full didactic recasts were used to show the learners the location of the errors that they made (2011). One example of the teacher's didactic recasts can be seen from the underlined statement below:

Extract 1

$\mathrm{T}$ : you forget ... do you know? maybe ... maybe you know something and then maybe we can add the story so it becomes a complete story (laughter) what happened to suro and boyo?

L6 : they fight

$\mathrm{T}:$ oh they fought and then?

The oral CF in the extract is taken as a didactic recast because the teacher's focus was on the learner's grammatical accuracy although the teacher understood what the learner said. The learner used the wrong form of verb in relation to the tense; the learners should have used past tense to tell a past event. Therefore, the teacher 
provided a didactic recast to show the correct form. This didactic recast is a full didactic recast because the teacher reformulated the whole utterance.

\section{b) Conversational Recasts}

A conversational recast is given when a teacher fails to understand what the learner is trying to say (Sheen and Ellis, 2011). It is said to be more implicit because it is given when there is a communication problem in understanding the speaker (or the learner) in such a way that the teacher usually reformulates the learner's utterance as how he or she intends to say (2011). Although it did not occur frequently, this type of recast still occurred in the classroom for both grammatical errors and lexical errors. One of the examples of the teacher's conversational recasts can be seen below:

Extract 2

L7 : why other artists (2) said that mister Duchamp art (1) was not art?

$\mathrm{T}$ : okay why did the other artists say that Marcel Duchamp's art ... was ... not ... art ... like that?

L7 : (nods)

The learner made a grammatical error in making a question. Due to the missing word 'did', the learner's utterance was not in the correct question form. Thus, the teacher tried to reformulate the learner's utterance like what she thought the learner was trying to say. This is included as a conversational recast because the aim of the teacher's correction was to understand the learner's utterance or the meaning.

\section{Explicit Correction}

Another type of oral CF strategies found in the conversation class is explicit correction. This type of correction is usually given by the teacher explicitly to guide the learners to the location of the error and supports learners with the correction of the error (Sheen and Ellis, 2011; Sheen, 2011). In the conversation class, explicit correction strategy was only given during exercises and games. The example of explicit correction in the conversation class is provided below:

Extract 3

L3 : I will watch a tv

$\mathrm{T}$ : you will watch tv ... you cannot say watch A tv

This $\mathrm{CF}$ is included as explicit correction because the teacher repeated the learner's erroneous utterance and provided the correction at the same time (e.g. it is A, not B). According to the teacher and learner's interaction in Extract 3, the learner made use of an incorrect article in her statement. When the learner had to complete a sentence, she added the article ' $\mathrm{a}$ ' before the word 'TV', which changed the meaning of her statement. The teacher, then, explicitly told the learner that her utterance was wrong, and the teacher also provided the correction. Moreover, the teacher made it clear by putting more emphasis on the location of the error to the learner.

\section{Explicit Correction with Metalinguistic Expla- nation}

Explicit correction with metalinguistic explanation refers to a teacher's explicit indication of a learner's error along with the provision of the correction and metalinguistic explanation about the error (Sheen and Ellis, 2011; Sheen, 2011). What makes this type different from explicit correction only is the provision of metalinguistic information about the learners' errors. One short interaction in the conversation class is seen to be showing explicit correction with metalinguistic explanation CF strategy for a learner's lexical error:

Extract 4

L1 : miss ... use both sides (of a piece of paper) itu recy ... recycle?

$\mathrm{T}$ : both ... it's reduce (3) it's like this ... reduce is like this ... if you need ... two pages but now you only use one page right this is reduce ... you need two pages for example to write uh ... two paragraphs but now you can use the first page and the second page that's reduce ... recycle ... recycle is like this...this is a piece of paper ... how can you recycle it? ... you have to put it (crushes a piece of paper) [(laughter)]

Although, as it is seen in Extract 4, the teacher does not repeat the erroneous part (as in 'It is not A, but it is B'), which is one of the characteristics of explicit correction, the teacher provided the correction explicitly to the learner since what the learner said was already incorrect. The learner made an error in choosing the word 'reduce' for 'recycle'. After explicitly saying the correction, further explanation was also given by the teacher so that the learner can distinguish the difference between the two words. Therefore, the teacher's $\mathrm{CF}$ provision is taken as explicit correction with metalinguistic explanation where the teacher informs the learner with the correction and the explanation at the same time. 


\section{Output-prompting CF}

\section{Clarification Requests}

This type of oral CF strategies is usually implicit where it gives signal to the learner that the teacher does not understand his or her utterance (Sheen and Ellis, 2011; Sheen, 2011). This correction can be given through signals, for instance by saying things like "Sorry?" or "Pardon me?" for clarification (Sheen, 2011, p. 3). This type of oral $\mathrm{CF}$ was also found in the conversation class. The teacher uses this strategy for both grammatical and lexical errors. The example below is an example of clarification request done by the teacher for a grammatical error during a conversation related to the topic in the class:

Extract 5

$\mathrm{T}$ : hah? to help you ... build something yes ... what else? let me write down what tools can help you ... tools ... can ... (writes on the board) can what Lauren?

L5: can be to ...

$\mathrm{T}$ : hah?=

L5 : =eh can help ... can help people=

The teacher's utterance (i.e. hah?) is regarded as a clarification request because its purpose was to clarify the learner's erroneous utterance and elicit correction from the learner. The learner made a grammatical error by saying 'can be to'. A signal (i.e. 'hah?') was given in a question tone by the teacher to tell that something was wrong. Through the teacher's signal, the learner realized that something was wrong and came up with the correction by herself.

\section{Repetition}

A repetition is one of oral CF strategies where a teacher repeats a learner's utterance, including the error, without giving any clue or information about the error (Sheen and Ellis, 2011; Sheen, 2011). The aim of doing repetition is to get the learner's attention and to encourage self-correction by the learner. Repetition found in the conversation class happened only during exercises or games in the classroom. A small part of the conversation class' interaction below shows the teacher's use of repetition:

Extract 6

L5 : $\quad$ doctors sus ... susters $=$

$\mathrm{T}:$ : =susters?!

The extract above shows the teacher's attempt in correcting a learner's lexical error during a game by using elicitation. The learner mixed a word in her L1 (i.e. suster - an Indonesian word for nurse) and suffix $-\mathrm{s}$ for plural form in English. As a response, the teacher repeated the error.

\section{Elicitation}

An elicitation is considered as a teacher's oral CF characterized by the use of a question to elicit correction from a learner (Sheen and Ellis, 2011; Sheen, 2011). It is also common that an elicitation usually comes along with the teacher's partial repetition of the learner's utterance in order to let the learner do the correction (Sheen, 2011). The elicitation strategy found in the conversation class occurred only during exercises and games for both grammatical errors and lexical errors of the learners. The writer provides an example of elicitation from the conversation class in this extract:

Extract 7

L6 : why why Marcel Duchamp ... the name is Marcel Duchamp?

LL: (laughter)

$\mathrm{T}$ : why ... can you fix your question please? why? (1)

An elicitation is seen from the extract. The teacher made use of question and partial repetition to elicit correction from the learner who made a grammatical error in creating a question. The teacher's elicitation started with the teacher's direct request to the learner to fix his utterance and repeated the word 'why?' from the learner's previous utterance.

\section{Metalinguistic Clue}

This type of oral CF strategies is included as the one of those that prompts the output (i.e. correction) from the learner (Sheen and Ellis, 2011; Sheen, 2011). Metalinguistic clue is shown when a teacher provides metalinguistic explanation to the learner's error without giving the correction (Sheen and Ellis, 2011; Sheen, 2011). An interaction during a classroom exercise in the following shows the teacher's attempts to give $\mathrm{CF}$ to a learner and one of them is by providing metalinguistic clue:

Extract 8

L7: why some artists said that (1) Marcel Duchamp's work ... was not art? (1)

$\mathrm{T}:$ okay ... why ... was (1) why can you fix it ... the [question?] $\rightarrow$ Elicitation

L6: [okay me] (raises his hand) why ... why Marcel Duchamp ... born in France?=

LL: [(laughter)]

$\mathrm{T}$ : $\quad$ no I think ... I think his question is good ... but it's not grammatically correct but Gaby do you understand the question?= $\rightarrow$ Metalinguistic clue

The teacher's CF is included as a metalinguistic clue because of the metalinguistic information that 
the teacher gave as a hint for the learner's error. The learner (L7) made a grammatical error in making his question. He got jumbled up with his words, which made his question grammatically incorrect. The learner missed the word 'did' in order to make a proper interrogative sentence in past tense. Thus, the teacher provided a metalinguistic clue to give an explicit signal that something is incorrect and it was a grammatical error.

In correcting the learners' errors, the teacher of the conversation class applied oral CF strategies to improve the learners' English and also taking the learners' affect into consideration. The teacher's action in providing the $\mathrm{CF}$ where she applied recast more often compared to the other CF strategies proves this. Recasts did not directly point the learners' errors. Without directly pointing out the errors, this was a safer way to correct sensitive learners. The learners were sensitive due to their early teenage years. According to the result of the interview, the learners in the intermediate conversation class was said to be not really active in talking, especially in English. If their mistakes were directly corrected in front of their classmates, they might speak less than usual. Thus, considerations on how to correct the learners' errors as well as not offending the learners were important for the teacher. On the other hand, an understanding of each of the learners' characteristics was also shown during the interview. An example was given by the teacher to show a comparison of two of her learners who had different characteristics. Learner A was said to be active in the class and cooperative in accepting the CF from the teacher, while learner $\mathrm{B}$ was taciturn and highly sensitive to $\mathrm{CF}$ to the point that learner B might not want to speak when $\mathrm{CF}$ was given by the teacher. Therefore, it is seen that the teacher would have more options in giving oral $\mathrm{CF}$ to learner A's errors compared to learner B's. Based on the classroom recordings, various oral $\mathrm{CF}$ strategies, including both inputproviding and output-prompting oral $\mathrm{CF}$ strategies were given to learner $\mathrm{A}$, while learner $\mathrm{B}$ was given recast. This point shows that oral $\mathrm{CF}$ was given to the learners with considerations, not just correcting the errors.

In correcting the learners' errors, the teacher also considered more on the learners' grammatical aspect than the vocabulary. According to the result of the interview, the importance of having good grammatical accuracy in speaking English was expressed by the teacher. The teacher believed that good grammatical accuracy showed how someone was well educated. Thus, this led the teacher to correct most of the learners' grammatical errors in the conversation class. It is also proven by the findings found in the classroom; most oral CF strategies were more motivated by the learners' grammatical errors than the lexical errors. Another point about this is still related to the learners' characteristics and learning styles. The learners of the conversation class were said to be mostly passive and rarely conversed in English on their own; in fact, the teacher was the one who dominated the communication in the classroom, for instance giving instruction and asking questions. The teacher herself also confirmed this during the interview. She discussed on how hard it was to make all the learners active in the conversation class; most of the time learners did not really give respond to the teacher. Thus, correcting the errors in the learners' utterances became the focus of the teacher rather than developing the flow of the conversation in the class. Therefore, the teacher ended up trying to remind the learners on their grammatical errors through the use of oral $\mathrm{CF}$ strategies although it was a conversation class.

\section{CONCLUSION}

Through this study, the writer was able to see the teacher's oral CF provision in the intermediate conversation class. The writer saw the teacher's preference in providing various oral $\mathrm{CF}$ strategies in the conversation class, in which more input-providing strategies were given for grammatical errors and more output-prompting strategies for lexical errors. The teacher's belief in the learners' moderate level of grammar had led the teacher to use input-providing CF for grammatical errors to remind the learners directly of the correct form. On the other hand, the learners' lexical use was treated with outputprompting strategies to let the learners explore the vocabulary for their speaking.

Next, the writer found that the teacher had made use of various oral CF strategies in her class; however, the teacher's use of oral CF strategies was not always efficient and effective. It was because the teacher chose to correct most of the learners' errors, including the same errors made repetitively in the class. There were times when the teacher repeated a CF strategy for the same error made by different learners. The teacher provided $\mathrm{CF}$ after the learners finished their speech. Instead, the teacher could make use of some of the class time to discuss about the major errors together with the learners to avoid repetition of the same error and CF strategy. Therefore, the writer 
realizes that the teacher's oral CF strategies were not always effective.

Third, the writer saw the teacher's supportiveness in facilitating oral $\mathrm{CF}$ for her learners. This was seen through the teacher's considerations on the learners (e.g. considering the learners' characteristics, learning styles, error, and age) and oral CF provision in the class. The teacher had proven this point by providing different CF strategies for different kinds of learners (e.g. responsive vs. sensitive learners). The result of the interview also unfolded the teacher's tendency to be cautious in giving corrections due to the learners' early teenage age, especially for less severe errors during talks that were not related to the material or the topic being discussed in order not to discourage the learners to speak English. Instead of correcting every single error, the teacher tended to choose the time to correct the learners' errors, for instance by providing CF during activities like games that was seen to be more useful since the learners would be more relaxed and able to get corrected for their errors.

Lastly, the writer found that most of the teacher's oral $\mathrm{CF}$ strategies in the classroom were aimed for the learners' grammatical accuracy. Although the learners had fewer problems in conveying their meaning, the teacher provided oral $\mathrm{CF}$ and focused more on the learners' form and language use in the conversation class. An emphasis on grammatical accuracy was also found in the interview. The writer, thus, saw this as the most probable reason for the teacher's oral CF provision for the learners' grammatical errors even though the main focus of the conversation class was to let the learners speak English comfortably.

\section{REFERENCES}

Dörnyei, Z. (2007). Research methods in applied linguistics: Quantitative, qualitative, and mixed methodologies. Oxford: Oxford University Press.

Elliott, J. (2005). Using narrative in social research: Qualitative and quantitative approaches. London, UK: Sage Publications, Ltd.

Ellis, R. (2009). Corrective feedback and teacher development. L2 Journal, 1, 3-18.

Littlewood, W. (1984). Foreign and second language learning: language acquisition research and its implications for the classroom. New York: Cambridge University Press.

Lyster, R., Saito, K., \& Sato, M. (2013). Oral corrective feedback in second language classrooms. Language Teaching, 46(1), 1-40. doi:10.1017/S0261444812000365.

Mackey, A., Park, H. I., \& Tagarelli, K. M. (2016). Errors, corrective feedback and repair: Variations and learning outcomes. In G. Hall (Ed.), the Routledge handbook of English language teaching (pp. 499-512). New York: Routledge.

Méndez, E. H., \& Cruz, M. d. R. R. (2012). Teachers' perceptions about oral corrective feedback and their practice in EFL classrooms. Profile Issues in Teachers' Professional Development, 14(2) 63-75.

Sheen, Y. (2011). Corrective feedback, individual differences and second language learning. Dordrecht: Springer.

Sheen, Y., \& Ellis, R. (2011). Corrective feedback in language teaching. In E. Hinkel (Ed.), Handbook of research in second language teaching and learning (Vol. 2, pp. 593-610). New York: Routledge. 